\title{
EL TRATAMIENTO DEL AUTOFAVORECIMIENTO DEL IMPUTADO. SOBRE LAS CONSECUENCIAS SUSTANTIVAS DEL PRINCIPIO DE NO AUTOINCRIMINACIÓN*
}

\section{JAVIER WILENMANN VON BERNATH**}

RESUMEN: El artículo reconstruye sistemáticamente los efectos del principio de no autoincriminación en el derecho penal sustantivo. Para ello, se muestra, en primer lugar, el sentido general del arreglo institucional "proceso penal adversarial" y su vínculo con la no autoincriminación. A partir de ello, el artículo da cuenta de la necesidad institucional de que el arreglo en cuestión no solo establezca reglas procesales relativas a formas de trato permitidas del imputado y actuaciones procesales inexigibles de este, sino también de que limite la aplicabilidad del castigo previsto por el sistema para la infracción de ciertas obligaciones de abstención de afectación a la administración de justicia respecto al imputado y sus cercanos. De esta forma, la determinación del efecto sistemático del principio de no autoincriminación en el derecho penal sustantivo se juega ante todo en la pregunta por el tratamiento de las distintas hipótesis de autofavorecimiento (procesal) de este. Así, el núcleo del artículo analiza los límites de la exclusión de pena al autofavorecimiento del imputado o de sus cercanos y la forma de tratamiento de los casos no cubiertos por estas limitaciones.

PALABRAS CLAVE: Derecho penal - derecho procesal penal - principio de no autoincriminación - obstrucción a la investigación - autofavorecimiento.

** Abogado, Licenciado en Ciencias Jurídicas y Sociales de la Universidad de Chile (Chile). Magister Legum Universität Regensburg (Alemania) Dr. Iur. Albert-Ludwigs-Universität Freiburg (Alemania) Profesor de la Facultad de Derecho de la Universidad Adolfo Ibáñez (CHILE) Correo electrónico: javier.wilenmann@uai.cl. 


\section{STRATEGIC BEHAVIOR OF THE DEFENDANT AND THE PRIVILEGE AGAINST SELF-INCRIMINATION. ABOUT THE CONSEQUENCES OF THE PRIVILEGE AGAINST SELF-INCRIMINATION ON SUBSTANTIVE CRIMINAL LAW}

ABSTRACT: The article aims at presenting a systematic treatment of the consequences of the privilege against self-incrimination in substantive criminal law. For this purpose, the article attempts to show that the privilege is part of an institutional arrangement which can be determined as "adversary criminal procedure system" in a broad sense. The institutional understanding of the object of the principle against self-incrimination enables the recognition of both, procedural and substantive rules, which are functional to the establishment to such a system. In the civil law tradition, this had led to the limitation of certain forms of punishment for perjury and obstruction of justice as well as strategic behavior of the defendant and its family. The article presents a systematic reconstruction of such limitations and the cases of strategic behavior which are not covered by the privilege.

KEYWORDS: Criminal Law - Criminal Procedure Law - privilege against self - incrimination, obstruction to justice - strategic behavior of the defendant.

Sumario: Introducción - 1) El principio de no autoincriminación y su estructura general de realización - (1.1.) Derecho a la defensa y principio de no autoincriminación como arreglos institucionales contingentes a un sistema de persecución penal - (1.2.) No autoincriminación en el derecho procesal penal (1.3.) Sistema de exenciones de consecuencias penales sustantivas derivadas del principio de no autoincriminación - 2) Delimitación de las consecuencias del principio de no autoincriminación en el derecho chileno: el autofavorecimiento agresivo - 3) Autofavorecimiento agresivo y exenciones de pena en el Código Penal chileno - Conclusiones - Bibliografia y jurisprudencia citada.

\section{INTRODUCCIÓN}

En las distinciones que tradicionalmente se realizan entre principios constitucionales que limitan las condiciones sustantivas de imposición de penas y principios constitucionales que informan la realización procedimental de la potestad de perseguir y castigar delitos, el principio de no autoincriminación es usualmente tratado como uno de los casos más claros de la segunda categoría, esto es, como principio del derecho procesal penal. Si uno revisa superficialmente la regulación constitucional, 
esta caracterización parece ser evidentemente correcta. Así, el artículo 19 número 7 letra f) de la Constitución Política de la República ("CPol”) -la disposición constitucional que más directamente tematiza al principio de no autoincriminación en el derecho chileno- asume de forma clara un punto de vista procesal: "En las causas criminales no se podrá obligar al imputado o acusado a que declare bajo juramento sobre hecho propio; tampoco podrán ser obligados a declarar en contra de este sus ascendientes, descendientes, cónyuges y demás personas que, según los casos y circunstancias, señale la ley”. La dimensión procesal de esta disposición puede notarse tanto por la forma de referencia al contexto (causas criminales) como por el hecho de tratarse de una regulación de procedencia de una forma de producción de prueba ("obligar a declarar bajo juramento"). También la legislación parece asumir la idea de que el principio de no autoincriminación es realizado por la ley procesal penal. Los artículos 93 letra g), 98, 305 y 340 inciso tercero del Código Procesal Penal (“CPP") parecen constituir las formas más relevantes de realización legal del principio constitucional en cuestión. El estudio de la no autoincriminación sería así ante todo competencia de la dogmática procesal penal.

La reconstrucción del principio de no autoincriminación como un asunto relevante de forma excluyente en el derecho procesal es, sin embargo, incorrecta. Si bien su origen y función se encuentran vinculados a un arreglo institucional específico en la constitución de un sistema de persecución penal, la forma que este adoptó en el derecho continental hace que su vínculo con el principio de no autoincriminación dependa ante todo del tratamiento penal sustantivo de ciertas actuaciones procesales. Las reglas sobre punibilidad del falso testimonio, del encubrimiento o de la obstrucción a la investigación, además de otros tipos desconocidos por el derecho penal chileno, como la simulación de delitos, fijan en buena medida las consecuencias sistemáticas centrales del principio de no autoincriminación. Su manifestación como "principio de no sanción del autofavorecimiento" -el nombre que uno puede darle a la vertiente sustantiva del principio de no autoincriminación- es así especialmente relevante. Los aspectos más problemáticos del principio de no autoincriminación se centran a su vez en aspectos sustantivos, en particular en la fijación de los límites del principio de no sanción del autofavorecimiento: jexiste algo así como completa irrelevancia sustantiva de las mentiras emitidas en el contexto de la persecución penal por un imputado o sus parientes y cercanos? ¿Tiene el imputado un derecho general a autofavorecerse, esto es, a realizar toda aquella actividad estratégica destinada a evitar su propia punición? Todas estas son preguntas que tienen importancia práctica crucial y que definen parte de la identidad de nuestras instituciones ligadas a la persecución, cuya respuesta tiene que venir dada por un análisis de derecho penal sustantivo y en las que el derecho procesal penal es más bien objeto de protección antes que objeto de regulación. 
El objeto de este artículo es realizar una reconstrucción sistemática del principio de no autoincriminación centrada no tanto en sus aspectos más directamente vinculados al derecho procedimental -obligaciones de trato y reglas de valoración de la prueba-, sino antes en su vertiente sustantiva de principio de no sanción del autofavorecimiento. Para ello, tras en primer lugar explicar el origen y el sentido de los arreglos institucionales ligados al sistema de cuya reconstrucción se trata (1.1.), así como dar brevemente cuenta de sus consecuencias propiamente procedimentales (1.2.), intentaré mostrar cómo el arreglo institucional en cuestión puede ser entendido como una regulación de la relación de tensión que se produce entre dos intereses contradictorios reconocidos por nuestros sistemas normativos, a saber, la protección de los recursos de la administración de justicia y el reconocimiento del principio de no sanción de las puras conductas estratégicas conducentes a evitar la sanción penal. Un análisis de la extensión de las exenciones de penas que el Código Penal (“CP”) reconoce en atención a la no sanción del autofavorecimiento permite inferir (con cierta imprecisión) la existencia de una estructura sistemática general de tratamiento de esta tensión institucional (1.3.). Los deberes positivos y negativos con la administración de justicia se ven redefinidos a partir del reconocimiento de la condición de imputado y de persona cercana a este. Esa redefinición afecta todas las conductas cuyo objeto sea la pura evitación de la persecución penal. En un segundo momento (2) se trata en cambio de determinar ahora con mayor precisión los límites de las consecuencias sustantivas del principio de no sanción del autofavorecimiento: ya que la estructura de realización de este principio solo afecta la punibilidad de conductas ligadas a la protección de recursos de la administración de justicia, aquello que puede ser denominado auto-favorecimiento agresivo no es objeto de exenciones de penas. Ello reproduce la estructura general que adopta el principio en el derecho penal y constitucional comparado. Tras reconstruir el núcleo del sistema de realización del principio de no sanción del autofavorecimiento, intentaré en un tercer momento (3) analizar brevemente la punibilidad de las conductas que se encuentran en sus márgenes.

\section{1) EL PRINCIPIO DE NO AUTOINCRIMINACIÓN Y SU ESTRUCTURA GENERAL DE REALIZACIÓN}

Como hemos visto, el tratamiento del sistema de reglas que nos interesa reconstruir tiene su origen en un principio que aparentemente compete ante todo al derecho procesal penal, a saber, el principio de no auto-incriminación ${ }^{1}$. El principio de no autoincriminación constituye una

Así también en el fondo Garrido Montt, Mario (2008) Derecho Penal Parte Especial, Tomo IV. Santiago: Editorial Jurídica, pp. 119-120 y 133. 
decisión constitucional ligada a un arreglo institucional mucho menos evidente de lo que su consideración natural actual sugiere. Esto es: más allá de que la práctica y la literatura actual tiendan a considerarlo como un "pilar esencial del sistema acusatorio"2 o como parte de todo Estado de derecho ${ }^{3}$, pese a la "extraña moralidad" que tiende criticársele, se trata más bien de la expresión de inmunización de un arreglo institucional relativamente reciente y cuyos contornos no son especialmente claros. Sin conocer el origen y la función de este arreglo institucional, el sistema de reglas en cuestión no puede ser comprendido en forma completa.

\section{(1.1.) DERECHO A LA DEFENSA Y PRINCIPIO DE NO AUTOINCRIMINA- CIÓN COMO ARREGLOS INSTITUCIONALES CONTINGENTES A UN SISTEMA DE PERSECUCIÓN PENAL}

Pese a conectar con la máxima latina nemo tenetur prodere seipsum, el principio de no autoincriminación es contingente al establecimiento de un sistema acusatorio de persecución penal ${ }^{4}$; este es parte de ese arreglo institucional ${ }^{5}$. Al revés, uno puede incluso considerar que el arreglo institucional denominado "sistema acusatorio" en sentido amplio es una consecuencia de la consagración de formas de trato estatal excluyentes de presión a la autoincriminación. Así no se trata solo de que una cierta concepción del modo correcto de ejercicio de la persecución penal incluya entre uno de sus componentes a la no autoincriminación, sino también de que su inclusión hizo necesaria una reformulación más o menos completa de las reglas de un sistema de persecución. Esto es especialmente

2 Corte Suprema Federal de los Estados Unidos, Malloy v. Hogan (1964), 378 U.S. 1,7; Murphy v. Waterfront Commission (1964), 378 U.S. 52, 55s.

3 Tribunal Constitucional Federal alemán en BVerfG 38, 105 en Neue Juristische Wochenschrift 1975, p. 103; o 116, 77 en Neue Juristische Wochenschrift 1981, p. 1431.

4 Como correctamente ha reconocido el Tribunal Constitucional, Sentencia Rol 2381-12 (2013) 20ss., se trata por lo mismo de una garantía aplicable solo a procedimientos a los que se asocia el riesgo de sufrimiento de una pena.

5 Por cierto, la historia del privilegio es mucho más compleja que un simple establecimiento ex nihilo durante las reformas del siglo XVIII y principios del siglo XIX. Ya el derecho común conocía y tematizaba la máxima nemo tenetur; en el derecho inglés, el privilegio de no declarar bajo juramento contra sí mismo fue, a su vez, utilizado como forma de lucha de la jurisdicción estatal contra la jurisdicción eclesiástica. Al respecto, Helmholz, R.H. (1997) "The Privilege and the Ius Commune: the Middle Ages to the Seventeeth Century." En Helmholz et al, The privilege against self-incrimination, Chicago: University of Chicago Press, pp. 17-20; y GraY, Charles M. (1997) "Self-Incrimination in Interjurisdictional Law: The Sixteenth and Seventeenth Centuries." En Helmholz et al, The privilege against self-incrimination, Chicago: University of Chicago Press, pp. 47ss. Pese a eso, el que el momento fundante en el establecimiento del privilegio moderno coincide con la constitución de un sistema acusatorio, es algo que también se deja afirmar sin dificultades en el common law. Véase Langbein, John (1997) “The Privilege and Common Law Criminal Procedure: The Sixteenth to the Eighteenth Centuries." en Helmholz et al, The privilege against self-incrimination. Chicago: University of Chicago Press, pp. 82 ss. 
claro si uno mira la historia del derecho procesal penal continental: este se ha visto determinado por la renuncia política a formas de trato que hicieran uso de la autoincriminación.

Para entender correctamente el origen y la función del principio de no autoincriminación y de sus manifestaciones penales sustantivas, uno puede presentar su contenido actual como expresión de un segundo estadio de evolución de la influencia de este principio en el sistema de persecución penal. Esta evolución puede ser descrita distinguiendo dos obligaciones: una obligación activa de declarar y una obligación pasiva de no declarar mentiras. Como intentaré mostrar a continuación, el sistema inquisitivo ${ }^{6}$, en el estadio previo al primer reconocimiento de un principio de no autoincriminación, se caracterizaba por consagrar ambas obligaciones: el imputado se encontraba activamente obligado a declarar y no debía declarar mentiras. El primer sistema reformado -el primer estadio de la evolución de cuya reconstrucción se trata- se caracteriza por eliminar la primera pero no la segunda obligación a través del reconocimiento del (puramente negativo) principio de no autoincriminación. El sistema reformado actual se caracteriza por eliminar completamente la primera obligación y redefinir la exigibilidad de la segunda respecto del imputado y de sus parientes. La corrección de esta descripción de la evolución histórica de nuestros arreglos institucionales puede ser entendida de mejor forma al ver con algo más de detalle la historia de estos cambios.

Uno puede observar esta verdadera transformación del sistema de forma clara en el derecho continental. En el sistema inquisitivo anterior al siglo XIX, la existencia de una obligación completa del imputado de colaboración con su propia persecución era constitutiva del sistema. La obligación de sinceridad del imputado en relación con su propia culpabilidad era, por lo mismo, natural.

La consagración de un sistema que asume institucionalmente que el imputado tiene un deber de colaboración leal con la persecución penal tenía dos tipos de manifestaciones. Su primera expresión era procedimental. En el proceso, la constitución de la confesión como regina probationum

\footnotetext{
No pretendo aquí referirme a la distinción entre un "modelo adversarial" y un "modelo inquisitivo" de la forma en que esta se utiliza imprecisamente para distinguir rasgos generales de los modelos de persecución y juicio penal en el mundo anglosajón y en el mundo de influencia continental. Al respecto véase el ya clásico (y algo desactualizado) estudio de Damaska, Mirjan (1973) "Evidentiary Barriers to Conviction and Two Models of Criminal Procedure: a Comparative Study." En University of Pennsylvania Law Review 121 N $^{\circ}$ 3, pp. 513ss. El apelativo "inquisitivo" juega aquí un rol de referencia histórica: se trata de una referencia a sistemas prerreformados de persecución penal. A este respecto véase solo LANGBeIn, John (1974) Prosecuting Crime in the Renaissance. Cambridge: Harvard University Press, pp. 129ss.
} 
se fundaba en la existencia de la obligación de sinceridad del imputado ${ }^{7}$. El cumplimiento de la obligación podía ser coactivamente exigido. Esa imposición coactiva se encontraba, sin embargo, reglada. Así, por ejemplo, la Carolina establecía no solo reglas procedimentales de apreciación de indicios de pruebas ligados a las declaraciones obtenidas luego de la aplicación de los apremios correspondientes, sino que en muchos casos condicionaba la procedencia de tortura a la realización de otros actos procedimentales anteriores y a la necesidad de su aplicación basada en la insuficiencia de los indicios ${ }^{8}$. Pese a ello, dada la insuficiencia general de otras formas de prueba orientadas a la determinación de la verdad de los hechos, el sistema dependía en buena medida de la confesión del imputado. La coacción a la confesión, incluyendo su regulación procedimental en la tortura ${ }^{9}$, encontraba su justificación precisamente en la posición jurídica del imputado como obligado a colaborar con la investigación: este se encontraba obligado a ser testigo contra sí mismo. La segunda manifestación de la posición jurídica del imputado en el proceso se refiere a la punibilidad de ciertas conductas desarrolladas en este. Sustantivamente, las conductas estratégicas del imputado que implicaran vulneración de la obligación en cuestión también podían ser castigadas (el así llamado castigo de la mentira, "Lügenstrafe") ${ }^{10}$. En lo esencial, se trataba en esto de la punibilidad del perjurio y, en los casos en que no era perseguible, del castigo divino que en cualquier caso le acompañaba ${ }^{11}$.

En la recepción de un principio de no autoincriminación en el derecho continental, la existencia de una posición del imputado en la que este se encontrara obligado a colaborar con su propia persecución no fue de inmediato eliminada. Al contrario, la reforma central del derecho fue antes la abolición de la exigibilidad directa de la obligación activa de declarar (la verdad) ${ }^{12}$, como parte del gran proceso político del siglo XVIII de abolición definitiva de la tortura, y no, en cambio, la supresión

\footnotetext{
7 Aselman, Maike (2004) Die Selbstbelastungs- und Verteidigungsfreiheit, Fráncfort del Meno: Peter Lang, pp. 25 ss. y 195-197.

$8 \quad$ Al respecto véase solo LANGBEIn (1974) 183ss.

9 Sobre la historia de la tortura como mecanismo definitorio del proceso penal prerreformado, véase el fundamental trabajo de Langbein, John (2006) Torture and the Law of Proof. Edición de bolsillo con un nuevo prefacio, Chicago: University of Chicago Press, pp. 3ss.

10 En todo, véase solo Fezer, Gerhard (1993) "Hat der Beschuldigte ein 'Recht auf Lüge'?" En Dencker et al. (eds.): Festschrift für Walter Stree und Johannes Wessels, Heidelberg: Müller, pp. 666-668. Sobre las formas de castigo antiguas de conductas asimilables a la imputación falsa o la simulación de delitos/obstrucción a la justicia véase MaUrach, Reinhart; SchroeDer, Friedrich-Christian; MaIwald, Manfred (2005) Strafrecht. Besonderer Teil, Tomo 2, 9a Edición, Heidelberg: Müller, pp. 478-479.

11 Sobre la historia del perjurio en relación con los cambios de arreglos institucionales ligados a la persecución penal, véase Wilenmann, Javier (2014b) "Sobre la estructura dogmática de los delitos de falsedad en el proceso". Ius et Praxis $20 \mathrm{~N}^{\circ} 2$, pp. 73 ss.

12 Sobre la abolición de la tortura véase LANGBEIn (2006) 10-12 y 61 ss.
} 
abstracta de dicha obligación ${ }^{13}$. La obligación en abstracto, en cambio, siguió siendo asumida como existente ${ }^{14}$. Incluso más: la carga al sistema que implicaba la desaparición de la tortura hizo funcionalmente necesaria la intensificación de la persecución penal a través de otros tipos también relacionados con la autoincriminación como, ante todo, el falso testimonio ${ }^{15}$. Pero la ausencia de coacción para hacer exigible el cumplimiento de la obligación de verdad daba, en la práctica, al menos un derecho a callar. El imputado mantenía, así, una obligación penalmente exigible de no declarar mentiras, pero la exigibilidad de la obligación de declarar la verdad había sido eliminada.

En el derecho inglés, la cuestión tuvo una evolución algo más compleja. Ya en el siglo XVIII fue consagrada una regla de exclusión del valor probatorio de la confesión obtenida bajo coacción, sin limitar el pleno valor probatorio de la confesión del imputado en los casos en que no se cumplieran las condiciones que definían esa forma de coacción prohibida (en lo esencial, promesa de favorecimiento o tortura) ${ }^{16}$. La evolución hacia la consagración de un "privilegio" de no autoincriminación vino dada por el complemento que a ello supuso la regla de la descalificación de interesados. De acuerdo a esta regla, la asunción de una posición de interés en el juicio -partes en el proceso civil, imputado en el proceso penal-implicaba descalificación de la condición probatoria de sus propias declaraciones. La adición de la regla de la descalificación de interesados a las limitaciones en la obtención de la confesión hizo que pese a la ausencia de una consagración completa del privilegio, en la práctica el imputado no pudiera afectar negativamente su propia persecución. Las partes tenían una obligación de guardar silencio como forma de resguardo del proceso y, paternalistamente, de ellos mismos en relación con la comisión de perjurio o falso testimonio. El imputado se encontraba, con ello, en algún sentido obligado a guardar silencio, pero ya no por consideración a

13 En detalle Pfenninger, H.F. (1957) "Die Wahrheitspflicht des Beschuldigten im Strafverfahren”. En Hohenleitner et al. (eds.): Festschrift für Theodor Ritter. Aalen: Scientia Verlag, pp. 357ss.; y Rogall, Klaus (1977) Der Beschuldigte als Beweismittel gegen sich selbst. Berlín: Duncker \& Humblot, pp. 17ss.

14 Véase también, con ulteriores referencias, DAMASKa (1973) 527 nota 41.

15 Véase Vormbaum, Thomas (1987) Der strafrechtliche Schutz des Strafurteils. Berlín: Duncker \& Humblot, pp. 83-91; Wilenmann, Javier (2014a) "El concepto de falsedad en el falso testimonio. Una introducción a la dogmática general de los delitos de falsedad”. Revista Chilena de Derecho 41 N $^{\circ}$ 1, pp. 59-60; EL Mismo (2014b) 75-77. Sobre la subsistencia de la obligación de verdad del imputado después de la reforma temprana del sistema de persecución penal, Fezer (1993) pp. 668ss.

16 Smith, Henry (1997) “The Modern Privilege: Its Nineteenth-Century Origins". En Helmholz et al. The privilege against self-incrimination. Chicago: University of Chicago Press, pp. 153-155. Véase también Langbein (2006), 8ss. y 73ss. Véase también Corte Suprema Federal de los Estados Unidos, Murphy v. Waterfront Commission (1964) 52, 58ss. 
sus derechos sino, al revés, por asunción general de no fiabilidad ${ }^{17}$. Solo la racionalización del proceso penal durante el siglo XIX consagró un verdadero privilegio a guardar silencio, cuya contracara es precisamente el restablecimiento de una relativa capacidad del imputado para constituir prueba contra sí mismo ${ }^{18}$.

En todo esto, en ningún caso existía una consagración de un derecho a autofavorecerse, sino solo de un derecho pasivo a no autoincriminarse. La redacción de la probablemente más famosa expresión del privilegio de no autoincriminación, la Quinta Enmienda de la Constitución de los Estados Unidos, es particularmente clara en el establecimiento de este vínculo. De acuerdo a este, "nadie puede ser constreñido a ser testigo contra sí mismo". El privilegio de no autoincriminación es literalmente una eliminación de la exigibilidad coactiva de la obligación de asumir una posición de testigo respecto de sí mismo: o, lo que es lo mismo desde el punto de vista de la valoración de la prueba, es expresión de una exigencia de voluntariedad de toda confesión penal.

El vínculo entre el proceso político de abolición de la tortura y la primera evolución del sistema de garantías procesales es, en esto, explícito y sigue teniendo vigencia: las manifestaciones propiamente procesales del principio de no autoincriminación son, como veremos, en lo esencial limitantes de la exigibilidad de ciertas actuaciones del imputado (esto es, limita la exigibilidad de aquellas actuaciones que puedan resultar incriminatorias) o de las consecuencias que pueden seguirse procesalmente en relación con esas actuaciones. Así, pese a ir más allá de la pura protección frente a la tortura, la insistencia en la calificación actual de la Quinta Enmienda como un derecho "a guardar silencio" sigue dando cuenta de este origen ${ }^{19}$. Como veremos a continuación, esta es la misma lógica que puede reconocerse en el derecho procesal penal chileno.

\section{(1.2.) NO AUTOINCRIMINACIÓN EN EL DERECHO PROCESAL PENAL CHILENO}

El privilegio de no autoincriminación parece tener relevancia ante todo en el proceso penal. Como hemos visto, ya las disposiciones constitucionales aplicables (artículos 19 número 3 inciso segundo, cuando uno lo extiende al derecho a la defensa, y 19 número 7 letra f) CPol) tienen una redacción que asume un contexto procesal. En todos estos casos, lo

Sмiтн (1997), p. 145-153.

Véase Dubber, Markus Dirk, (2004) "The Criminal Trial and the Legitimation of Punishment", en Duff et al. (eds.), The Trial on Trial, Tomo I. Oxford: Hart Publishing, pp. 93-94. En los Estados Unidos, la insistencia en Miranda v. Arizona (1966) 384 U.S., 436 como la interpretación crucial de la Quinta Enmienda es particularmente expresiva de esto. Véanse también las referencias relativas a la descripción del privilegio en Helmholz (1997) 2. 
central es la exigibilidad de ciertas actuaciones procesales. También el origen histórico de la garantía y la existencia de múltiples disposiciones procesales penales ( $y$, en parte, también procesales generales) que consagran limitaciones a la forma de ejercicio de la persecución penal en el proceso dan cuenta de este énfasis procesal del principio de no autoincriminación $y$, en general, del derecho a la defensa jurídica ${ }^{20}$. En general, esas disposiciones admiten ser agrupadas en dos: disposiciones relativas a la prueba y a la valoración de la prueba (artículo 98 en relación con 326; artículo 302 y 305, ante todo artículo 340 inciso final CPP), por una parte, y, por la otra, disposiciones de trato del imputado (por ejemplo: artículo 91, artículo $93 \mathrm{~g}$ ) CPP), las que también tienden a tener incidencia probatorio en caso de infracción.

En parte, estas manifestaciones siguen siendo expresivas del viejo derecho a callar. El énfasis del crucial artículo 93 g) CPP en relación con la cuestión puramente pasiva de guardar silencio es expresivo del mantenimiento de la fijación en el lado pasivo del privilegio, lo que es propio del tratamiento procesal penal de este. Lo mismo sucede en las situaciones en que la posición de testigo puede implicar autoincriminación: el artículo 305 CPP, llamativamente nombrado "principio de no autoincriminación", se concentra en establecer un derecho a no responder preguntas que puedan incriminar, es decir levanta la obligación constitutiva de la posición de testigo de declarar. En relación con la obligación relativa al contenido de las declaraciones, las manifestaciones procesales del principio de no autoincriminación no tienen referencia directa. En particular, el artículo 98 inciso tercero CPP sigue consagrando una especie de obligación simbólica de sinceridad ("exhortar a decir la verdad"). Lo central en el establecimiento del segundo tipo de manifestación del principio de no autoincriminación es, por ello, antes una cuestión sustantiva penal que procesal penal. El sistema tiende a eliminar las consecuencias que se siguen de las obligaciones de sinceridad que impone el sistema cuando su cumplimiento implica autoincriminación.

La fijación del derecho procesal penal en extensiones pasivas del privilegio no implica que no se haya producido un cambio categórico en la interpretación de la extensión del derecho a la defensa y del principio de no autoincriminación. Pero ese cambio categórico se manifiesta en materia penal sustantiva. Esto es: solo la evolución posterior tendió a transformar al privilegio pasivo de no autoincriminación en un derecho limitado

20 Entre nosotros, también la literatura asume que se trata de un campo tematizado ante todo por el derecho procesal. Véase, por muchos, Zapata (2005) "El cinturón de seguridad del derecho a guardar silencio/prestar declaración del detenido: la intervención oportuna y efectiva del defensor". Revista de Estudios de la Justicia No 5, pp. 258ss.; Horvitz y López (2004), Derecho Procesal Penal Chileno. Tomo II. Santiago: Editorial Jurídica, pp. 80ss. También Tribunal Constitucional Sentencia Rol 2381-12 (2013) 20ss. 
de autofavorecimiento, cuya extensión es fijada por el derecho penal sustantivo antes que por el derecho procesal penal.

\section{(1.3.) Sistema de EXENCIONES DE CONSECUENCIAS PENALES SUSTAN- TIVAS DERIVADAS DEL PRINCIPIO DE NO AUTOINCRIMINACIÓN}

En general, el privilegio de no autoincriminación se manifiesta en materia sustantiva penal a través de una exención de pena respecto de ciertos tipos. Esto sucede ante todo respecto del falso testimonio (artículo 206 inciso final CP) y de la obstrucción a la investigación (artículo 269 bis inciso final). En el caso del falso testimonio, su estructura revela de forma clara la organización sistemática del principio de no autoincriminación. Mientras la variante procesal (en el caso procesal penal: el artículo $305 \mathrm{CPP}$ ) exime de la obligación de declarar pero no califica la obligación relativa al contenido de la declaración, el artículo 206 inciso final CP levanta las consecuencias penales que se siguen de la infracción de la obligación relativa al contenido (declarar la verdad) ${ }^{21}$ : el testigo no puede ser castigado por falso testimonio si la declaración verdadera "pudiere acarrear un riesgo de persecución penal (suya o de un parientes)". Esto es: la variante activa tiende a ser competencia del derecho procesal, mientras la variante relativa al contenido, en general reconstruible como obligación pasiva (no declarar algo falso), es competencia penal sustantiva. La razón de esto es clara. Las obligaciones relativas al contenido de declaraciones y actuaciones procesales son en general establecidas por tipos penales. Así, la obligación de sinceridad del testigo se manifiesta ante todo en el tipo de falso testimonio. Como la sanción por incumplimiento de esa obligación es determinada por completo por el derecho penal sustantivo, lógicamente solo el propio derecho penal sustantivo puede recalificar las condiciones de producción de esa sanción.

Más allá de la exención de pena en los artículos 206 y 269 bis CP, el Código Penal consagra una especie de exención similar en el caso del encubrimiento en el artículo 17 inciso final CP. Por la estructura misma del encubrimiento, esa exención se aplica solo a parientes y no, en cambio,

21 En esto, es completamente irrelevante si uno reconstruye la obligación de cuya infracción depende la punibilidad del falso testimonio con o sin referencia al juramento (haciendo del falso testimonio siempre un delito de perjurio). Aunque una reconstrucción de esta clase es abiertamente incompatible con el derecho vigente, ella tendría que llegar en cualquier caso a la misma conclusión respecto a las limitaciones que se siguen del principio de no autoincriminación. Su razonamiento sería el siguiente: el falso testimonio es punible por infringir el juramento. El juramento, sin embargo, no es exigible en los casos de peligro de autoincriminación o incriminación de parientes -la propia Constitución Política lo señala en el artículo 19 número 7 letra f) y en el inciso final del artículo 206 CP-, con lo que con independencia de que el imputado o su pariente haya jurado o no, este es inválido para efectos penales por su situación. 
al autor o partícipe mismo del delito. Esto tiene una explicación estructural más o menos obvia. El tratamiento del encubrimiento como figura de las reglas sobre participación de la Parte General implica que en él hay accesión a un injusto ajeno. Si el injusto admite ser visto como propio (principal o auxiliar), la cuestión de la accesión por encubrimiento simplemente no se plantea.

En la consagración de esta variante sustantiva del privilegio de no autoincriminación (o, en su caso, incriminación de parientes), el derecho chileno confirma completamente la evolución general comparada de este. Más allá de la exención de pena a los parientes en caso de encubrimiento incluida en el Código Penal desde su texto original, cuyo reconocimiento resulta necesario dada la estructura misma del encubrimiento chileno, el falso testimonio no conocía exenciones de pena hasta 2005. Solo el artículo $2^{\circ}$ de la Ley 20.074, adecuatoria de la reforma procesal penal ${ }^{22}$, introdujo la exención que hoy conoce el artículo 206 CP. En el caso de la obstrucción a la investigación, el artículo 269 bis CP conocía desde su introducción por la Ley 19.077 (entonces: obstrucción a la justicia) una exención de pena similar a la existente actualmente (aunque con referencia al antiguo artículo 201 del Código de Procedimiento Penal, el que de la misma forma que el artículo 302 CPP establecía las exenciones de la obligación de declarar de parientes del reo). La consagración comparativamente temprana de la exención de pena en el caso de la antigua obstrucción a la investigación no es, pese a sus apariencias, una excepción a la evolución general, en el sentido de que consecuencias pasivas (eliminación de obligaciones de colaboración) de la no autoincriminación anteceden a las consecuencias activas (eliminación de consecuencias negativas por ciertos actos de autofavorecimiento). La obstrucción a la justicia, en la forma que conoció hasta la Ley 20.074, era consagratoria de un deber activo de colaboración con la investigación ${ }^{23}$. Ese deber activo es el que era levantado por la exención de pena hasta el 2005, cuando la obstrucción a la investigación pasó a ser consagratoria de una obligación puramente pasiva. Con ello, en la primera recepción del privilegio de no autoincriminación, su consagración era necesaria: se trataba del levantamiento de una obligación de colaboración con la incriminación propia o de un pariente. Algo similar sucede con la exención de la obligación de declarar del imputado y de los parientes en el antiguo Código de Procedimiento Penal. No es que el sistema chileno no levantara antes de la Ley 20.074 la

\footnotetext{
22 Sobre los fines de la Ley 20.074, véase con mayor detalle Ossandón, María Magdalena (2008) "Los delitos de obstrucción a la investigación". En Rodríguez Collao (ed.) Delitos, pena y proceso. Libro homenaje a Tito Solari Peralta. Santiago: Editorial Jurídica, pp. 421 ss. y 429ss. Las actas de historia de ley se encuentran disponibles en http://www.leychile.cl/Consulta/portada_hl?tipo_norma $=X X 1 \&$ nro_ley $=20074$ Con mayor detalle Ossandón (2008) 431-432 y 440.
} 
obligación activa central vinculada al testimonio, esto es, la obligación de declarar. Al contrario, una exención de esta obligación existía, por cierto, al menos desde la promulgación del Código de Procedimiento Penal (en el caso de los testigos: artículo 222, posterior 201, del Código de Procedimiento Penal). Pero en cuanto pura eliminación de la obligación activa de declarar de los parientes, su posición admite ser vista dentro de la primera evolución del sistema de persecución penal. La Ley 20.074 extendió los efectos de esta exención, en cambio, a parte de la obligación pasiva del testigo (no hacer declaraciones falsas).

Esta evolución compleja también permite explicar el extraño contenido de la exención del artículo 269 bis CP. De acuerdo a este, se encuentran exentas de pena "las personas a que se refieren el inciso final del artículo 17 de este Código y el artículo 302 del Código Procesal Penal". Transcrito, estas personas son: "(los encubridores de su) cónyuge o de sus parientes legítimo por consanguinidad o afinidad en toda la línea recta y en la colateral hasta el segundo grado inclusive, de sus padres o hijos naturales o ilegítimos reconocidos (...)" (artículo 17 CP) y "el cónyuge o el conviviente el imputado, sus ascendientes o descendientes, sus parientes colaterales hasta el segundo grado de consanguinidad o afinidad, su pupilo o guardador, su adoptante o adoptado" (302 CPP). Al analizar este listado, debiera ser inmediatamente llamativa la ausencia del propio imputado en la lista. El privilegio de no autoincriminación es ante todo un derecho del imputado; este derecho puede tener, por cierto, efecto reflejo en los parientes, pero no es un privilegio exclusivo de estos. La no inclusión expresa del imputado se encuentra presente en toda la corta historia de los delitos de obstrucción a la justicia/obstrucción a la investigación en Chile. En esto, el error parece derivarse de haber adoptado un sistema de referencias relativo al testimonio y al encubrimiento. Esta forma de referencia funciona respecto del falso testimonio por la razón sencilla que, a diferencia del derecho anglosajón, el imputado (y la parte en materia civil) no puede ser testigo. Como el falso testimonio es un delito especial propio $^{24}$, la exclusión del imputado tiene lugar por no ser autor posible del delito y no requiere de limitación a causa del privilegio de no autoincriminación. Algo similar sucede en el caso del encubrimiento. El autor o partícipe no necesitan ser privilegiados, como reconocimiento de una ausencia de obligación de perjudicarse a sí mismo respecto a la persecución del Estado, porque no pueden acceder a un injusto ajeno si el injusto es propio. En cambio, esta forma de tratamiento no funciona en la obstruc-

24 A este respecto véase solo WiLENMANN (2014b) 96ss. 
ción a la justicia/investigación, la que constituye un delito común e independiente del injusto original ${ }^{25}$.

El principio de no autoincriminación parece funcionar sistemáticamente en materia sustantiva penal eliminando la pena que se sigue de todas las infracciones a obligaciones de colaboración de particulares con la administración de justicia. Los dos tipos en los cuales hay consagración del privilegio de no autoincriminación -el falso testimonio y la obstrucción a la investigación- constituyen delitos contra la administración de justicia. En el primero, se protege la precaria posición de la administración de justicia en relación con la determinación de hechos pasados por medio de la consagración de un ámbito de sinceridad en el proceso. En el caso de la obstrucción a la investigación, se protege la escasez de los recursos de la persecución penal frente a su desviación y, con ello, dilapidación por la entrega de información falsa ${ }^{26}$. En ambos casos, los deberes

25 Ossandón (2008) 440 y 455-456, intenta subsanar el problema legislativo por la vía de considerar que hay un concurso aparente entre autoencubrimiento, impune, y obstrucción a la investigación. Más allá de lo ingeniosa que resulta la solución, ella es abiertamente insostenible: el encubrimiento no es un delito en el derecho chileno, sino una forma de intervención punible. Como tal, el concurso aparente es simplemente inaplicable: el delito original (hurto, robo, homicidio, etc.) no tiene ninguna relación sistemática con la obstrucción a la investigación que haga posible la doble calificación aparente que caracteriza al concurso aparente. La propia Ossandón parece darse cuenta de las dificultades de su interpretación y, por ello, señala que en realidad se trata de un caso de inexigibilidad de otra conducta. Esa conclusión es correcta dentro de los límites que el ordenamiento jurídico declara inexigibles las conductas de renuncia al autofavorecimiento, a saber, cuando no afectan bienes jurídicos ulteriores y, en particular, de terceros.

26 Al respecto, con mayor detalle, Wilenmann, Javier (2011) "La administración de justicia como un bien jurídico". Revista de Derecho de la Pontificia Universidad Católica de Valparaíso No 36, pp. 568ss. Esta forma de reconstrucción funcional de la obstrucción a la justicia (en el caso alemán: de la simulación de delitos) es estándar en Alemania. Véase solo Geerds, Friedrich (1985) "Kriminelle Irreführung der Strafrechtspflege - Über strafrechtliche und kriminologische Probleme von Falschverdächtigung, Deliktsvortäuschung und Strafvereitelung (\$\$ 164, 145 d, 258, 258 a StGB)”. Juristische Ausbildung 1985, p. 617 y 621; FAHrRENHOST, Irene (1987) "Grenzen strafloser Selbstbegünstigung”. Juristische Schulung 1987, pp. 707-708; Geppert, Klaus (2000) “Zu einigen immer wiederkehrenden Streitfragen im Rahmen des Vortäuschens einer Straftat (\$145 d StGB)". Juristische Ausbildung 2000, pp. 383-384; StüвInger, Stephan (2004) “Die Vortäuschung einer Straftat ( $\$ 145$ d StGB). Legitimationsprobleme einer Strafnorm”. En Goltdammer's Archiv für Strafrecht 2004, pp. 339, 343-344; Dietmeier, Frank (2003) “\$ 145 d”. En Matt y Renzikowski (eds.), Strafgesetzbuch Kommentar. Múnich: Vahlen, Nm. 1; NK-Schild Wolfgang y Kretschmer, Bernhard (2013) “\$ 145 d." En Kindhäuser et al (eds.), NomosKommentar zum Strafgesetzbuch, Tomo 2, 4a Edición, Baden-Baden: Nomos, Nm. 1 y 4; Zopfs, Jan (2012) “\$ 145 d". En Joecks y Miebach (eds.), Münchener Kommentar zum Strafgesetzbuch, Tomo 3, 2a edición, Múnich: Beck, Nm. 1-5; Rudolphi Hans Joachim, y Rogall, Klaus (2009) "\$ 145 d". En Wolter (ed.), Systematischer Kommentar zum Strafgesetzbuch, Tomo III, 7a Edición, 58. Distribución, Colonia: Carl Heymanns, Nm. 2; Sternberg-Lieben, Detlev (2010) “\$145b." En Eser et al (eds.), Schönke/Schröder Strafgesetzbuch Kommentar, 28 a Edición, Múnich: Beck, Nm. 1; Russ, Wolfgang (2009) "\$ 145 d". En Laufhütte et al. (eds.) Leipziger Kommentar zum Strafgesetzbuch, 12. Edición, Berlín: De Gruyter, Nm.1; KindhäusER, (2010) Strafgesetzbuch. Lehr-und Praxiskommentar. 4a Edición, Baden-Baden: Nomos, $\$ 145$ d Nm. 1; EL 
correlativos a los tipos en cuestión admiten ser reconstruidos como deberes generales, es decir, no relativos a un cargo determinado. Por supuesto, el falso testimonio es técnicamente un delito especial propio, ya que depende de la tenencia de la posición personal “testigo". Pero la posición de testigo es en sí misma reflejo de un deber general de colaboración con la administración de justicia, aplicable también y ante todo a particulares. Por ello, se trata en ambos casos de deberes que se dejan designar como generales. Estos deberes generales con la administración de justicia son aquellos que se ven afectados por las consagraciones sustantivas del principio de no autoincriminación. Los deberes de colaboración activa con la administración de justicia a través de la declaración (y de la ausencia de falsedad en la declaración) y pasiva con la persecución penal a través de la prohibición de entrega de antecedentes falsos son justamente limitados en relación con parientes del imputado.

La forma de consagración del privilegio de no autoincriminación en materia penal sustantiva parece poder ser descrita así de forma sencilla con la siguiente fórmula: el incumplimiento punible de obligaciones de colaboración con la administración de justicia deja de ser punible respecto de sí mismo y de parientes. Como se verá, esta descripción es imprecisa y engañosa.

\section{2) DELIMITACIÓN DE LAS CONSECUENCIAS DEL PRINCIPIO DE NO AUTOINCRIMINACIÓN EN EL DERECHO CHILENO: EL AUTO- FAVORECIMIENTO AGRESIVO}

En el caso del autofavorecimiento (o favorecimiento de un pariente), es decir de las acciones estratégicas efectuadas por el autor o por sus parientes para evitar su declaración de culpabilidad, la fórmula imprecisa de tratamiento de las tensiones entre no autoincriminación y protección de la administración de justicia tiene consecuencias relevantes que, pese a su imprecisión, son fácilmente reconocibles. El autofavorecimiento solo puede resultar de entrada excepcionalmente impune, cuando su ejercicio solo sea constitutivo de un delito contra la administración de justicia derivado de obligaciones generales. En cambio, si hay afectación de bienes jurídicos ulteriores, la calidad de autofavorecimiento de la acción constitutiva de delitos es irrelevante. Esto es ya intuitivamente evidente: "es con seguridad correcto afirmar que no existe una causa de justificación por situación procesal 27 ". Aunque el Estado pueda reconocer un margen de acción estratégica del imputado para evitar su propia condena, nadie

Mismo (2012) Strafrecht. Besonderer Teil I. 5a Edición, Baden-Baden: Nomos, $\$ 53$ Nm. 1; Maurach/Schroeder/Maiwald (2005) 478; Wessels/Hettinger (2010) Strafrecht Besonderer Teil 1. 34a Edición, Heidelberg: Müller, $\$ 16$ Nm. 705. 
dudaría que el homicidio de testigos claves no se encuentra privilegiado ni exento de pena en ningún sentido. No es que el principio de no autoincriminación o el derecho a la defensa no tengan entidad suficiente para eximir la pena pese a que resulten aplicables en caso de homicidio de testigos claves; el privilegio simplemente no resulta aplicable del todo en una situación de esta clase. Lo mismo sucede cuando lo afectado son bienes jurídicos colectivos distintos de la administración de justicia. Si el autor o imputado altera documentos públicos para favorecerse en un proceso penal en su contra, la condición de autofavorecimiento del delito de falsedad documental no tiene incidencia sobre su punibilidad. Todo ello cae simplemente fuera del ámbito de aplicación del privilegio de no autoincriminación o del derecho a una efectiva defensa.

Tampoco es correcto, sin embargo, sostener que la condición de autofavorecimiento de la acción constitutiva de delito implique siempre eliminación de la aplicabilidad de delitos contra la administración de justicia derivados de deberes generales. Esto puede ser explicado fácilmente por referencia al delito de denuncia o acusación calumniosa (artículo 211 $\mathrm{CP})$. El delito de acusación o denuncia calumniosa es un delito que afecta a la vez la administración de justicia y bienes jurídicos individuales del afectado. En el caso de la administración de justicia, la denuncia o acusación falsa implica malgasto de trabajo y recursos escasos del Estado (en particular, de las policías y del Ministerio Público), al igual en que en la obstrucción a la justicia del artículo 269 bis CP. La evitación de la dilapidación de esos recursos es lo que protege el artículo $211 \mathrm{CP}$ en su lado supraindividual. Al mismo tiempo, su mayor pena frente al artículo 269 bis CP solo puede ser explicada por la afectación adicional de bienes jurídicos individuales del perjudicado, ya que de otra forma su disvalor de injusto sería exactamente el mismo. Si la condición de autofavorecimiento de una acción implicara eliminación de la aplicabilidad de las penas que sancionan el incumplimiento de obligaciones generales de colaboración con la administración de justicia, el artículo $211 \mathrm{CP}$ no debiera resultar aplicable o, al menos, debiera dar lugar a una atenuación importante de la pena. Toda otra solución es sistemáticamente insostenible.

La única interpretación sistemáticamente consistente del efecto del privilegio de no autoincriminación en la calificación penal sustantiva de las acciones constitutivas de autofavorecimiento consiste, por ello, en sostener que este redefine las obligaciones de colaboración con la administración de justicia. Dentro de ciertos márgenes, las obligaciones no son exigibles por aplicación del privilegio de no autoincriminación. Excedidos esos márgenes, las obligaciones en cuestión y las penas que se sigue de su incumplimiento son plenamente aplicables.

Esto es una solución fácilmente reconocible en el derecho comparado. En el derecho alemán, por ejemplo, el autofavorecimiento se encuentra tematizado en lo esencial por tres tipos: la simulación de delitos 
(Vortäuschen einer Straftat, $\$ 145$ d del Código Penal alemán, "StGB"28), la imputación falsa (Fälsche Verdächtigung, $\$ 164$ StGB $^{29}$ ); y el encubrimiento (Strafvereitelung, $\left.\$ 258 \mathrm{StGB}^{30}\right)^{31}$. Cuando el autofavorecimiento

28 "(1) El que contra su leal saber y entender simule ante una oficina u autoridad competente para recibir denuncias que:

1. un hecho antijurídico habría sido cometido, o;

2. que la comisión de uno de los supuestos antijurídicos del inciso primero del $₫ 126$ sería inminente, será castigado con pena privativa libertad de hasta tres ańos o con multa, siempre que el hecho no se encuentra conminado con pena de acuerdo a los $\$ 164,258$ o 258 a.

(2) También será castigado quien contra su leal saber y entender intente engañar a las autoridades establecidas en el inciso primero respecto a los intervinientes

1. en un hecho antijurídico o

2. en uno de los inminentes hechos antijurídicos establecidos en el $\$ 126$ inciso 1.

(3) Será castigado con pena privativa de libertad de entre 3 meses y 5 ańos el que

1. realice uno de los supuestos establecidos en el inciso primero número 1 . o segundo inciso primero o

2. contra su leal saber y entender simule ante una de las autoridades establecidas en inciso primero que la realización de uno de los supuestos antijurídicos establecidos en el $₫ 46 \mathrm{~b}$ inciso primero frase 1 No 2 de este Código o en el $\$ 31$ frase 1 No 2 de la Ley sobre estupefacientes es inminente, $o$

3. contra su leal saber y entender intenta engañar a una de estas autoridades respecto a la inminencia de la realización de un hecho de acuerdo al № 2, para conseguir una atenuación o prescindencia de la pena de acuerdo a los $\$ 46$ b de este Código o 31 de la Ley de Estupefacientes.

(4) En casos menos graves del inciso tercero, la pena será privativa de libertad de hasta 3 años o multa”.

29 (1) El que contra su leal saber y entender atribuya a otro ante una autoridad o funcionario competente para recibir denuncias o públicamente la comisión de un hecho antijurídico o la lesión de un deber del cargo, con la intención de gatillar un procedimiento u otras medidas estatales en contra de este o hacer que estas se mantengan, será castigado con pena privativa de libertad de hasta 5 años o con multa.

(2) Será de igual forma castigado el que ante las mismas autoridades establecidas en el inciso primero o en público, con la misma intención y contra su leal saber y entender, realice afirmaciones fácticas adecuadas para gatillar un procedimiento $\mathrm{u}$ otras medidas estatales en contra de este o para hacer que estas se mantengan.

(3) Será castigado con pena privativa de libertad de entre 6 meses y 10 ańos el que cometa la imputación falsa con la intención de obtener una atenuación de la pena o una prescindencia de esta de acuerdo al $\$ 46$ b de este Código o al $\$ 31$ de la Ley de Estupefacientes. En casos menos graves, la pena será de entre 3 meses y 5 años.

30 (1) El que intencionalmente o con conocimiento impida total o parcialmente que otro sea castigado o se le imponga una medida ( $\$ 11$ inciso primero No 8$)$ de acuerdo a la ley penal por un hecho antijurídico, será castigado con pena privativa de libertad de hasta 5 años o con multa.

(2) De la misma forma será castigado el que intencionalmente o con conocimiento impida total o parcialmente la ejecución de una pena o medida impuesta a otro.

(3) La pena no puede ser superior a la pena con que se encuentra conminado el hecho antijurídico anterior.

(4) La tentativa es punible.

(5) No será castigado por encubrimiento el que mediante el hecho intente total o parcialmente impedir ser castigado o sujeto a una medida o que una pena o medida que le haya sido impuesta sea ejecutada.

(6) El que cometa el hecho en provecho de un pariente se encuentra exento de pena.

31 Una exposición conjunta de la forma en que la administración de justicia protege sus recursos a través de estos tres tipos puede encontrarse en GeERDs (1985) 617ss.; o en Wessels/ Hettinger $(2010) \$ 16$ Nm. 686ss. 
implica solo la afectación de la posibilidad de punición del propio sujeto, es decir es solo constitutivo de encubrimiento, la conducta de encubrimiento del propio delito es siempre impune ( $\$ 258$ No 5 StGB). Esto es una consecuencia necesaria de la recepción del principio de no auto-incriminación: el simple autofavorecimiento, equivalente a las hipótesis de encubrimiento del propio delito en el derecho chileno -las que por supuesto son formalmente irrelevantes entre nosotros por motivos de técnica legislativa ${ }^{32}$, no puede ser castigado ${ }^{33}$, ya que de otra forma todo acto de defensa que implique puesta en duda falsa de la culpabilidad sería constitutiva de delito. La cuestión se altera, en cambio, en los casos en que además de afectar la posibilidad del castigo propio, la conducta implique afectación adicional de los recursos de la administración de justicia (tanto en el $\$ 145 \mathrm{~d}$ como en el $\$ 164 \mathrm{StGB}$ ) y/o puesta en peligro de un tercero $(\$ 164$ StGB necesariamente y, de forma contingente, $\$ 145 \mathrm{~d}$ inc. 2 StGB). La solución jurisprudencial y dogmáticamente aceptada es hacer punible el autofavorecimiento en todas las hipótesis que impliquen falsa imputación de otro ( $\$ 164$ StGB) o desvío de la actividad persecutoria hacia otro ( $\$ 145 \mathrm{~d}$ inc $2 \mathrm{StGB}$, con limitaciones reseñadas más abajo) ${ }^{34}$.

Por supuesto, esta solución alemana no es sistemáticamente necesaria. El texto del $₫ 145$ d StGB permite extender la punición a todos los casos que sean subsumibles en su ámbito de aplicación sin ser aplicable el encubrimiento o la imputación falsa. Con ello, sería formalmente admisible una interpretación que sostuviera que la punibilidad se extiende también a los casos en que haya causación de desperdicio de recursos de la persecución sin desvío hacia un tercero. La literatura y la jurisprudencia han limitado, sin embargo, la aplicabilidad del $\$ 145$ d StGB precisamente a los casos en que hay desvío hacia un tercero sin ser constitutivo de imputación falsa.

Esta solución tiene su origen en una interpretación del principio de no autoincriminación. La razón que hace necesaria establecer limitaciones en el castigo por el autofavorecimiento con efecto de dilapidación de recursos de la persecución y desvío hacia un tercero -en particular, en los casos del $\$ 145$ d inc. 2 StGB, equivalentes a nuestro 269 bis CP-,

32 Esas razones de técnica legislativa dicen relación con las dos formas de tratamiento histórico-dogmático del encubrimiento: como forma de participación incluida en las reglas de la Parte General (modelo antiguo) o como delito autónomo contra la administración de justicia (modelo contemporáneo). En el modelo antiguo, la cuestión de la punibilidad del encubrimiento de delito propio tiende a no plantearse, ya que requiere de ausencia de intervención de otra forma (es decir, como autor o partícipe) en el injusto encubierto. En el modelo contemporáneo, en cambio, la inserción de una regla de exclusión es necesaria. Sobre las dos formas de tratamiento del encubrimiento, véase con mayor detalle Ossandón (2008) 424-425.

33 Así expresamente Rogall (1977) 38.

34 Véanse las referencias en la nota a pie de página siguiente. 
es que la declaración de punibilidad más extensa afectaría el núcleo del privilegio de no autoincriminación. La mera negación de la intervención propia en un hecho punible puede implicar pragmáticamente imputación a un tercero, con lo que la afirmación general de la punibilidad conforme al $\$ 145$ d inc. 2 StGB podría implicar afectación de un principio del Estado de derecho. Ejemplo (clásico): En la investigación de un accidente de tránsito con resultado de muerte en el que los dos pasajeros del automóvil que causó el accidente se encontraban ebrios al momento de los hechos, la mera negación de la posición de chofer implica necesariamente atribución de esa posición al otro pasajero. Con ello, una interpretación amplia del $\$ 145$ d inc. 2 StGB (o incluso del $\$ 164$ StGB) limitaría la posibilidad de defensa: el simple hecho de negar la propia culpabilidad implicaría imputación a tercero, con lo que la consagración de una regla de no aplicabilidad del privilegio por cualquier acto de imputación impediría siquiera afirmar la propia inocencia. La solución de la jurisprudencia alemana y de la dogmática dominante es solo hacer punible el autofavorecimiento a través de imputación de tercero si ella es constitutiva, al menos, de una "negación calificada": no basta ni la negación simple ni la afirmación de las consecuencias lógicas de la negación, sino que tiene haber imputación directa de otro o una falsificación de la situación probatoria tal que tenga entidad suficiente para producir el efecto de desviar el foco persecutorio al otro ${ }^{35}$. Si se cumplen los requisitos del autofavorecimiento calificado, la conducta es completamente punible de acuerdo al $\$ 164$ StGB, primariamente aplicable, o subsidiariamente de acuerdo al $\$ 145 \mathrm{~d}$ inc. 2 StGB. Lo convincente de esta interpretación pese a los complejos problemas de cruce que se producen en este ámbito pueden ser apreciados por el grado de aceptación que la solución tiene en dogmática y jurisprudencia.

Al igual que en Chile, en Alemania el principio de no autoincriminación fija así límites dentro de los cuales la abstención de autofavorecimiento no es exigible. "La actividad de las autoridades encargadas de la persecución penal se encuentra libre de protección respecto de influencias

35 Así Hoffmann, Dieter (1965) Die Selbstbegünstigung. Kiel: Rechts- und staatswissenschaftliche Fakultät, pp. 192ss.; Fahrrenhost (1987) 707-710; Fezer (1993) 663-684; Geppert (2000) 387-388; Aselman (2004) 258 ss.; Dietmeier (2013) \$ 145d Nm. 17; Zopfs (2012), 145d Nm. 34-36; Rudolphi/Rogall (2009), \$ 145 d Nm. 27; Rogall (1977), 39; Sternberg-Lieben (2010) \$145b Nm. 15; Russ (2009), \$ 145d Nm. 1618; KindhäUser (2010), $₫ 145$ d Nm. 13.; el mismo (2012) $₫ 53$ Nm. 17-18; Wessels/ Hettinger (2010), \$16 Nm. 713-714; Arzt, Günther; Weber, Ulrich; Heinrich, Bernd y Hilgendorf, Eric (2009) Strafrecht. Besonderer Teil, Bielefeld: Gieseking, \$ 48 Nm 27. Más lejos SAAL, Martin (1997) Das Vortäuschen einer Straftat (\$ 145 d StGB) als abstraktes Gefährdungsdelikt. Berlín: Duncker \& Humblot, 182 ss., quien considera que el $\$ 145$ b inciso segundo StGB es aplicable a todos los supuestos de declaraciones falsas sobre la intervención. 
del imputado siempre que solo se trate de la conducción del proceso concreto. Las investigaciones pueden ser afectadas, falseadas o destruidas por él; corrección, completitud, celeridad, efectividad de la actividad de persecución no se encuentran protegidas penalmente respecto del imputado $36 "$. Pero “(e)1 $\$ 164$ StGB muestra que la influencia del imputado encuentra sus límites allí donde la acción de autofavorecimiento lesiona bienes jurídicos de otro". Esto quiere decir que el derecho reconoce un privilegio a favorecerse a sí mismo "mientras el comportamiento solo se dirija contra su persecución penal o la ejecución de la pena a su respecto, no en cambio, en los casos en que el comportamiento de autofavorecimiento afecte bienes jurídicos ulteriores ${ }^{37}$ ". Una conclusión de esta clase es casi unánimemente aceptada por la literatura alemana.

En España, una interpretación de esta clase del alcance del privilegio en casos de autofavorecimiento ha sido explícitamente reconocida tanto por el Tribunal Constitucional como por el Tribunal Supremo. En el caso del Tribunal Supremo, en su sentencia No 243 de 25 de enero de 2013, este declaró explícitamente que

El hecho de que el procesado no esté obligado por juramento o promesa a decir verdad y que no pueda ser reo de falso testimonio, no supone que pueda mentir y acusar a otros de manera impune. Las acusaciones inveraces a otros imputados pueden ser constitutivas de un delito de acusación y denuncia falsa (...).

En esto, el Tribunal Supremo Español se basó expresamente no solo en una línea jurisprudencial de no exclusión de la imputación falsa en caso de autofavorecimiento, sino en la jurisprudencia del Tribunal Constitucional en relación a la inexistencia de un derecho a mentir del imputado (STC 142/2009), pese a que la mentira en cuestión solo sea punible en casos que afecten intereses de terceros.

Pese a la ausencia de tratamiento dogmático del problema en nuestro medio, no hay razones para concluir algo distinto en el derecho chileno. La plena punibilidad de la imputación falsa constitutiva de autofavorecimiento (artículo $211 \mathrm{CP}$ ) es demostrativa de la forma racional en que el principio de autoincriminación se manifiesta en el ordenamiento jurídico. Este es relevante cuando la conducta de autofavorecimiento es expresiva del derecho a disputar la propia culpabilidad ${ }^{38}$. Si la conducta va más allá,

36 FEZER (1993) 674.

37 Schild/Kretschmer (2013) \$145d Nm. 4. Una formulación idéntica puede encontrarse por ejemplo en la importante monografía de Rogall (1977) 38.

38 Explícito Rudolphi, Hans Joachim (1979) "Strafverteitelung durch Verzögerung der Bestrafung und Selbstbegünstigung durch Vortäuschen einer Straftat”, en Juristische Schulung, pp. 862-863: "En todas las situaciones en que la conducta de autofavorecimiento solo se di- 
esta cae simplemente fuera del ámbito de aplicación del privilegio, por lo que en los casos de obstrucción a la investigación constitutivos de una hipótesis de simulación de delitos (incluyendo simulación de participación de otro), el privilegio no es aplicable ${ }^{39}$. En otras palabras: la conducta estratégica ofensiva respecto de terceros cae simplemente fuera del ámbito del nemo tenetur ${ }^{40}$ : ella no es una forma aceptable de defensa y, por ello, no es reconocida por el Estado de derecho como constitutiva del privilegio de no autoincriminación ${ }^{41}$. Precisamente por ello es que es usual que la particular peligrosidad que supone la motivación de autofavorecimiento -ella es constitutiva de un motivo en sí para afectar intereses protegidos de terceros inocentes- cuente como condición de punición o incluso como motivo de agravación de la pena en el derecho comparado ${ }^{42}$.

La solución sistemática presente en el derecho penal del common law a los problemas de cruce entre no sanción del autofavorecimiento y afectación de bienes jurídicos ulteriores es mucho más extrema que en el derecho continental ${ }^{43}$. En los Estados Unidos, la Corte Suprema ha interpretado que incluso el testimonio en la investigación que niega falsamente sustentos de la propia culpabilidad (el así llamado "simple no exculpatorio") no caen dentro de protección constitucional y, por lo mismo, son punibles por falso testimonio si las leyes estatales formalmente lo permiten ${ }^{44}$. Dada la particular evolución del derecho del common law, en el que

rige contra la imposición o ejecución de la pena, como en los $\$ 258$ y 120 StGB, ella no es punible. (...) La decisión legislativa es siempre la contraria en los casos en que la conducta de autofavorecimiento implique afectación de bienes jurídicos ulteriores no implicados en la relación inicial."

39 Schild/Kretschmer (2013) \$ 145 d Nm. 4; Rudolphi (1979) 863.

40 Geppert (2000) 385-386.

41 Paradójicamente, durante la tramitación de la Ley 20.074 el profesor Jorge Bofill (BiblioteCa del Congreso Nacional, Historia de la Ley $N^{\circ} 20.074$, pp. 309-311) propuso limitar la obstrucción a la justicia a los supuestos de afectación de intereses de terceros con propósito de mejoramiento de la propia posición en la persecución, es decir, precisamente aquello que aquí se ha denominado autofavorecimiento agresivo. El legislador no adoptó por completo esta solución, no por considerar por cierto que al imputado no le fuera exigible abstenerse de esas conductas, sino porque consideraba que la propuesta era demasiado restrictiva y quiso ampliar el tipo.

42 Véanse los ejemplos de Rudolphi (1979), p. 863 y Fahrenhost (1987) 707.

43 Esto no quiere decir, por cierto, que el derecho norteamericano o anglosajón sea en general más abierto a aceptar evidencia autoincriminatoria que el derecho continental. Así, a diferencia de buena parte de los sistemas procesales, la garantía anglosajona se extiende también a otra clase de soportes en los que se contengan declaraciones autoincriminatorias del imputado. Véase Damaska (1973) 526-527 nota 40.

44 Así expresamente en Brogan v. United States, en 522 U.S. 398 (1998). En él, la Corte Suprema no solo admite la posibilidad de punibilidad del no exculpatorio falso si, como en el caso en revisión, ello resulta subsumible en la legislación estatal, reafirmando con ello una larga línea jurisprudencial respecto a que "ni el texto ni el espíritu del privilegio de no autocriminación compulsiva de la Quinta Enmienda confieren un derecho a mentir" o que "la correcta invocación de la Quinta Enmienda le permite a un testigo permanecer en silencio, no en cambio a mentir bajo juramento". Esta afirma además que frente al "cruel trilema" 
el falso testimonio del imputado es en general formalmente posible ${ }^{45}$, ello hace que el ámbito de punición sea particularmente extenso. Lo mismo sucede en las hipótesis recurrentes en que el imputado declara como testigo respecto de otro imputado, en general con el objeto de favorecerse a partir de la desviación de culpabilidad a otro. Si la declaración es falsa, no hay ninguna razón sustantiva que excluya la punibilidad ${ }^{46}$. La vertiente sustantiva del principio de no autoincriminación es por ello en el derecho penal del common law particularmente débil. Su relevancia se concentra en la cuestión procesal relativa al deber de declarar del todo.

Las conclusiones que pueden ser sacadas de estas dos primeras secciones se dejan resumir fácilmente. No existen razones constitucionales para extender el ámbito de acción estratégica permitida del imputado a los casos en que haya afectación de bienes jurídicos individuales o colectivos distintos de la administración de justicia, incluyendo aquellas situaciones en las cuales se cree una situación probatoria falsa tal que ello tenga entidad para desviar la actividad persecutoria hacia un tercero. Al contrario, una interpretación del privilegio de no autoincriminación que vaya tan lejos - desconocida en el mundo occidental- pondría en peligro la viabilidad del privilegio mismo. La aceptación del autofavorecimiento por imputación formal o informal falsa de otro implicaría, por el incentivo que supone el autofavorecimiento, una puesta en peligro general frente a la persecución penal.

\section{3) El AUTOFAVORECIMIENTO A TRAVÉS DE IMPUTACIÓN FALSA DE OTRO EN EL DERECHO CHILENO}

Si bien no existen razones constitucionales para extender el principio de no sanción del autofavorecimiento a los supuestos de desviación de recursos de persecución hacia un tercero, su tratamiento conforme a las reglas del Código Penal tiene complejidades propias. Es crucial, por ello, poder determinar cuál es el tratamiento penal aplicable a los supuestos aquí denominados como autofavorecimiento agresivo (o, siguiendo la terminología alemana, los supuestos en que al menos hay negación calificada con efecto sobre tercero).

El autofavorecimiento por imputación falsa de tercero, como situación típica ideal, se deja describir de la siguiente forma. El autor de un delito desvía el foco persecutorio de sí mismo a través de la entrega de

de frente a la pregunta por la propia culpabilidad tener que "admitir culpabilidad, cometer perjurio o contentarse", el otorgamiento del derecho a permanecer en silencio es la única solución reconocida (522 U.S. 398, 404). Véase también LaFave, Wayne (2010) Criminal Law. 5a Edición, St. Paul: West Academic Publishing, 180-181.

45 Pfenninger (1957) 366ss.

46 Véase Fezer (1993) 670. 
información falsa a las autoridades encargadas de la persecución. La información entregada tiene por objeto incriminar a un tercero como parte de la estrategia de desviación. La relativa frecuencia criminológica de esta conducta hace que sea un problema dogmático penal tratado con relativa frecuencia en el derecho comparado. En Chile no parece haber, en cambio, tratamiento dogmático de este tipo.

La situación típica ideal descrita puede, en abstracto, subsumirse en dos tipos: la imputación falsa (denuncia o acusación calumniosa en Chile) y la obstrucción a la investigación (simulación de delitos por medio de engaño sobre los intervinientes en Alemania). En general, ambos tipos se relacionan entre sí de forma similar a la relación que tienen hurto y robo. La imputación falsa es un tipo con requisitos de punibilidad más estrictos y con una pena más elevada que el supuesto básico de obstrucción a la investigación (269 bis CP inciso primero), salvo parcialmente en la hipótesis de imputación falsa de una falta. Así, mientras la pena prevista para la acusación o denuncia calumniosa en el artículo $211 \mathrm{CP}$ es de presidio menor en su grado máximo, medio o mínimo, dependiendo respectivamente de si el delito imputado es crimen, simple delito o falta, y multa, la pena prevista para la obstrucción a la investigación es, en general, equivalente a la denuncia o acusación calumniosa de falta. La única situación en que la penalidad de la imputación falsa de delito o crimen no es más elevada que en la obstrucción a la investigación es en el caso de la producción del resultado ulterior previsto en el inciso segundo del artículo 269 bis CP, en cuyo caso la estructura es precisamente similar a la de la imputación falsa: no hay pura afectación a la administración de justicia, sino también a bienes jurídicos individuales (por solicitud de medidas cautelares o acusación), con lo que las condiciones de punibilidad son también más exigentes. Existiendo una relación de esta clase, el artículo 269 bis inciso segundo CP y el artículo $211 \mathrm{CP}$ en la hipótesis de imputación de simple delito se encuentran en relación de alternatividad: el concurso se siempre aparente, ya que las estructuras y disvalores de injustos son equivalentes, pero la subsidiariedad del 269 bis CP frente al $211 \mathrm{CP}$ ya no es necesaria.

Parte de los requisitos adicionales que producen la calificación de la imputación falsa en la situación normal se explican por la necesidad de identificar condiciones bajo las cuales intereses individuales del tercero sean efectivamente afectados. Esto es precisamente lo que también se da en el caso del artículo 269 bis inciso segundo CP. En Alemania, el gran requisito que distingue ambos tipos (y que, de hecho, explica la tipificación del engańo respecto a los partícipes en el $\$ 145$ d inc. 2 StGB) es el 
requisito de determinación del imputado falsamente ${ }^{47}$. Mientras el $\$ 145$ d inc. 2 StGB se satisface sin necesidad de determinación de otro partícipe, el $\$ 164$ StGB requiere de determinación de este. En lo demás, los requisitos son similares: (i) la acción debe tener lugar ante una autoridad con competencia para recibir denuncias; y (ii) la acción debe tener entidad suficiente para desviar recursos de la persecución penal hacia la persecución del tercero. Precisamente ello explica el que el derecho alemán haga explícita la relación entre ambos tipos: de acuerdo al $\$ 145 \mathrm{~d}$ inc. 1 frase final StGB, la conducta solo es punible conforme a dicha disposición si no es punible de acuerdo al $\$ 164$ StGB.

En Chile, la conducta de autofavorecimiento por imputación falsa de tercero también se deja subsumir dentro de los dos tipos correspondientes: el artículo $211 \mathrm{CP}$ y el artículo 269 bis CP. Aunque la estructura del artículo $211 \mathrm{CP}$ es particularmente indeterminada, en el caso del artículo 269 bis CP, esta reproduce claramente la estructura ya identificable en el derecho alemán. La acción consiste en (i) aportación de antecedentes falsos al Ministerio Público; (ii) que obstaculicen el esclarecimiento del hecho punible o sus intervinientes; (iii) a través de la existencia de un vínculo objetivo entre esa aportación falsa y la desviación de la actividad persecutoria. Aquí también lo central es el vínculo entre acción del imputado y dilapidación de recursos de la persecución penal. Por supuesto, los antecedentes falsos dolosamente entregados al Ministerio Público pueden consistir en la identidad del supuesto responsable del delito, en cuyo caso el tipo también puede subsumirse en el artículo $211 \mathrm{CP}$. Esto hace que la relación de subsidiariedad también se dé en el derecho chileno: si el autofavorecimiento por inculpación falsa de terceros tiene determinación suficiente para constituir una imputación, el artículo $211 \mathrm{CP}$ es primariamente aplicable (salvo en la excepción de alternatividad cuando se cumplen a la vez los requisitos de la imputación falsa de simple delito y los requisitos del artículo 269 bis inciso segundo CP). De no cumplirse los presupuestos del artículo $211 \mathrm{CP}$, solo es aplicable el artículo 269 bis CP. Bajo supuestos de autofavorecimiento agresivo, el privilegio de no autoincriminación es simplemente inaplicable.

La falta de aplicabilidad del privilegio es, por supuesto, formalmente evidente en el caso del artículo 211 CP. Pero ella también tiene lugar incluso formalmente en el artículo 269 bis CP. Quienquiera sostener que la argumentación desarrollada en este artículo es sustantivamente convincente pero contradictoria con la falta de distinción en el artículo 269 bis inciso final CP entre situaciones de autofavorecimiento normal y autofavorecimiento agresivo, incluido el artículo 269 bis inciso segun-

47 Sobre la historia del $\int 145$ d StGB en relación con el $\int 164$ StGB, véase solo STÜBINGER (2004) 340-341. 
do CP, pasa por alto el hecho que dicha disposición solo hace referencia a las personas a que se refieren el inciso final del artículo 17 del CP y el artículo 302 del CPP. En ninguno de los dos casos hay referencia al autor/ imputado, en los términos penales y procesales penales respectivos. Si esto constituye un error, su solución por vía interpretativa general -esto es, incluyendo tanto el caso del imputado como de sus parientes- solo puede darse en los supuestos en que la construcción de una interpretación no cubierta explícitamente por la norma pero que abarque in bonam partem a este sea justificable. La primera parte de esta opinión ya demostró que no solo no existen razones para no aplicar el derecho a la defensa y el privilegio de no autoincriminación a las situaciones de autofavorecimiento que implican afectación de intereses de terceros, sino que una conclusión de este tipo es peligrosa en relación con el mismo principio que pretenden aplicar. Si, por ello, aquello que justifica con razón incluir al imputado entre los favorecidos por el artículo 269 bis inciso final es el derecho a la defensa y el principio de no autoincriminación, entonces esa razón simplemente no resulta aplicable cuando el autofavorecimiento es agresivo. Esto ya es de por sí una buena razón para introducir una distinción en el inciso final del artículo 269 bis CP: dicha exclusión de penalidad tiene buenos motivos para ser aplicada en los supuestos en que la entrega de antecedentes falsos no implique afectación de intereses ulteriores. Esto es así, por ejemplo, no solo en los casos de negación de participación, sino también cuando hay construcción de una relación de hechos falsa. En estos casos, hay buenas razones para aplicar formalmente la regla del inciso final a los parientes y, por extensión interpretativa, al imputado. En casos, en cambio, en que la estrategia de defensa sea agresiva con intereses ulteriores, el inciso final del artículo 269 bis CP tiene que ver limitada interpretativamente su extensión.

\section{CONCLUSIONES}

1. La exclusión de pena en algunos supuestos de autofavorecimiento o de favorecimiento persecutorio de parientes por parte del ordenamiento jurídico (artículos 269 bis inciso final CP y 206 inciso final CP) es una consecuencia de la evolución del estándar de defensa garantizado por el Estado desde el puro reconocimiento al derecho pasivo a no declarar en contra de uno mismo, al reconocimiento de un estándar estratégico también activo de comportamiento defensivo frente a la persecución penal del Estado.

2. La determinación de la extensión activa de ese estándar, en particular en el levantamiento de obligaciones tales como no declarar mentiras o no aportar antecedentes falsos a investigaciones penales, no es compe- 
tencia principal del derecho procesal penal, sino del derecho penal sustantivo. En materia penal sustantiva, el Estado exime de toda pena todo comportamiento estratégico del imputado que afecte a la propia administración de justicia, sin afectar, en cambio, bienes jurídicos ulteriores. En caso de exceder este estándar y poner en peligro bienes jurídicos ulteriores, la obligación inicial también respecto de la administración de justicia vuelve a ser plenamente aplicable y su infracción plenamente sancionable. Ello es demostrado con claridad por la ausencia de rebaja de pena en los supuestos del artículo $211 \mathrm{CP}$ cuando ello tiene por objeto favorecer la propia posición persecutoria.

3. La limitación reseñada en la extensión de la aplicabilidad del estándar de defensa garantizado también a comportamientos estratégicos, en el sentido de que solo produce efectos si no afecta bienes jurídicos ulteriores, es unánimemente reconocida en el derecho penal comparado revisado (alemán, español y del common law). El autofavorecimiento agresivo, incluyendo el caso especial de imputación falsa de otro, no se encuentra privilegiado en ningún sentido y un privilegio de esta clase no resulta en caso alguno justificable. Dependiendo de las circunstancias de su realización, este puede ser perseguido como imputación falsa (211 CP) o como obstrucción a la investigación (269 bis inciso segundo CP).

\section{BIBLIOGRAFÍA}

Aselman, Maike (2004) Die Selbstbelastungs- und Verteidigungsfreiheit, Fráncfort del Meno: Peter Lang.

Arzt, Günther; Weber, Ulrich; Heinrich, Bernd y Hilgendorf, Eric (2009) Strafrecht. Besonderer Teil, Bielefeld: Gieseking.

Biblioteca del Congreso Nacional, Historia de la Ley No 20.074, en http://www.leychile.cl/Consulta/portada_hl?tipo_norma=XX1 \&nro_ ley $=20074$

Damaska, Mirjan (1973) "Evidentiary Barriers to Conviction and Two Models of Criminal Procedure: a Comparative Study". En University of Pennsylvania Law Review $121 \mathrm{~N}^{\circ} 3$.

DietMeier, Frank (2003) “ $\$ 145$ d." En Matt y Renzikowski (eds.), Strafgesetzbuch Kommentar. Múnich: Vahlen.

Dubber, Markus Dirk (2004) "The Criminal Trial and the Legitimation of Punishment", en Duff et al. (eds.), The Trial on Trial, Tomo I. Oxford: Hart Publishing.

FahrRenhost, Irene (1987) "Grenzen strafloser Selbstbegünstigung." Juristische Schulung. 
Fezer, Gerhard (1993) "Hat der Beschuldigte ein 'Recht auf Lüge'?" En Dencker et al (eds.): Festschrift für Walter Stree und Johannes Wessels, Heidelberg: Müller.

Garrido Montt, Mario (2008) Derecho Penal Parte Especial, Tomo IV,

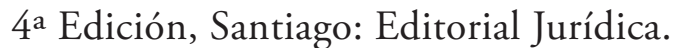

GeERds, Friedrich (1985) “Kriminelle Irreführung der Strafrechtspflege - Über strafrechtliche und kriminologische Probleme von Falschverdächtigung, Deliktsvortäuschung und Strafvereitelung ( $\$ \$$ 164, 145 d, 258, 258 a StGB)”. Juristische Ausbildung.

Geppert, Klaus (2000) "Zu einigen immer wiederkehrenden Streitfragen im Rahmen des Vortäuschens einer Straftat ( $\$ 145$ d StGB).” Juristische Ausbildung.

Gray, Charles M. (1997) "Self-Incrimination in Interjurisdictional Law: The Sixteenth and Seventeenth Centuries". En Helmholz et al, The privilege against self-incrimination, Chicago: University of Chicago Press.

Helmholz, R.H. (1997) "Introduction". En Helmholz et al, The privilege against self-incrimination, Chicago: University of Chicago Press.

Helmholz, R.H. (1997) "The Privilege and the Ius Commune: the Middle Ages to the Seventeeth Century". En Helmholz et al, The privilege against self-incrimination, Chicago: University of Chicago Press.

Hoffmann, Dieter (1965) Die Selbstbegünstigung. Kiel: Rechts- und staatswissenschaftliche Fakultät.

Horvitz, María Inés; y López, Julián (2004) Derecho Procesal Penal Chileno. Tomo II. Santiago: Editorial Jurídica.

Kindhäuser, Urs (2010) Strafgesetzbuch. Lehr- und Praxiskommentar. $4^{\mathrm{a}}$ Edición, Baden-Baden: Nomos.

Kindhäuser, Urs (2012) Strafrecht Besonderer Teil I. 5a Edición, BadenBaden: Nomos.

LaFave, Wayne (2010) Criminal Law. 5a Edición, St. Paul: West Academic Publishing.

Langbein, John (1974) Prosecuting Crime in the Renaissance. Cambridge: Harvard University Press.

Langbein, John (1997) “The Privilege and Common Law Criminal Procedure: The Sixteenth to the Eighteenth Centuries". En Helmholz et al., The privilege against self-incrimination. Chicago: University of Chicago Press.

Langbein, John (2006) Torture and the Law of Proof. Edición de bolsillo con un nuevo prefacio, Chicago: University of Chicago Press.

Maurach, Reinhart, Schroeder, Friedrich-Christian, Maiwald, Manfred (2005) Strafrecht. Besonderer Teil Tomo 2, 9a Edición, Heidelberg: Müller. 
Ossandón, María Magdalena (2008) "Los delitos de obstrucción a la investigación”. En Rodríguez Collao (ed.), Delitos, pena y proceso. Libro homenaje a Tito Solari Peralta. Santiago: Editorial Jurídica.

Pfenninger, H.F. (1957) "Die Wahrheitspflicht des Beschuldigten im Strafverfahren". En Hohenleitner et al (eds.), Festschrift für Theodor Ritter. Aalen: Scientia Verlag.

Politoff, Sergio, Matus, Jean Pierre, Ramírez, María Cecilia (2011) Lecciones de Derecho Penal. Parte Especial. Reimpresión segunda edición, Santiago: Editorial Jurídica.

Rogall, Klaus (1977) Der Beschuldigte als Beweismittel gegen sich selbst. Berlín: Duncker \& Humblot.

Rudolphi, Hans Joachim (1979) "Strafvereitelung durch Verzögerung der Bestrafung und Selbstbegünstigung durch Vortäuschen einer Straftat - BayObLG NJW 1978, 2563”. En Juristische Schulung.

Rudolphi, Hans Joachim, y Rogall, Klaus (2009) “\$ 145 d.” En Wolter (ed.), Systematischer Kommentar zum Strafgesetzbuch, Tomo III, 7a Edición, 58. Distribución, Colonia: Carl Heymanns.

Russ, Wolfgang (2009) "\$ 145 d". En Laufhütte et al. (eds.) Leipziger Kommentar zum Strafgesetzbuch, 12a Edición, Berlín: De Gruyter.

SAAL, Martin (1997) Das Vortäuschen einer Straftat (\$ 145 d StGB) als abstraktes Gefährdungsdelikt. Berlín: Duncker \& Humblot.

Schild, Wolfgang y Kretschmer, Bernhard (2013) "\$ 145 d". En Kindhäuser et al. (eds.), NomosKommentar zum Strafgesetzbuch, Tomo 2, 4a Edición, Baden-Baden: Nomos.

SchneIder, Hartmut (1991) Grund und Grenzen des strafrechtlichen Selbstbegünstigungsprinzips. Berlín: Duncker \& Humblot.

SMith, Henry (1997) "The Modern Privilege: Its Nineteenth-Century Origins". En Helmholz et al. The privilege against self-incrimination. Chicago: University of Chicago Press.

Sternberg-Lieben, Detlev (2010) “\$ 145 d.” En Eser et al. (eds.), Schönke/Schröder Strafgesetzbuch Kommentar, 28a Edición, Múnich: Beck.

StüBINGER, Stephan “Die Vortäuschung einer Straftat ( $\$ 145$ d StGB). Legitimationsprobleme einer Strafnorm”. En Goltdammer's Archiv für Strafrecht 2004.

Vormbaum, Thomas (1987) Der strafrechtliche Schutz des Strafurteils. Berlín: Duncker \& Humblot.

Wessels, Johannes, y Hettinger, Michael (2010) (Strafrecht Besonderer Teil 1). 34a Edición, Heidelberg: Müller.

Wilenmann, Javier (2011) "La administración de justicia como un bien jurídico". Revista de Derecho de la Pontificia Universidad Católica de Valparaiso No 36. 
Wilenmann, Javier (2014a) "El concepto de falsedad en el falso testimonio. Una introducción a la dogmática general de los delitos de falsedad". Revista Chilena de Derecho $41 \mathrm{~N}^{\circ} 1$.

Wilenmann, Javier (2014b) "Sobre la estructura dogmática de los delitos de falsedad en el proceso". Ius et Praxis $20 \mathrm{~N}^{\circ} 2$.

Zapata, María Francisca (2005) "El cinturón de seguridad del derecho a guardar silencio/prestar declaración del detenido: la intervención oportuna y efectiva del defensor", Revista de Estudios de la Justicia No 5.

Zopfs, Jan (2012) "\$ 145 d". En Joecks y Miebach (eds.), Münchener Kommentar zum Strafgesetzbuch, Tomo 3, 2a edición, Múnich: Beck.

\section{JURISPRUDENCIA CITADA}

Tribunal Constitucional, Sentencia Rol 2381-12 (2013).

Corte Suprema Federal de los Estados Unidos, Malloy v. Hogan (1964), 378 U.S. 1.

Corte Suprema Federal de los Estados Unidos, Murphy v. Waterfront Commision (1964), 378 U.S. 52.

Corte Suprema Federal de los Estados Unidos, Miranda v. Arizona (1966), 384 U.S. 436.

Corte Suprema Federal de los Estados Unidos, Brogan v. United States (1998), en 522 U.S. 398

Tribunal Constitucional Federal Alemán, BVerfG 38, 105 en Neue Juristische Wochenschrift 1975, p. 103.

Tribunal Constitucional Federal Alemán, BVerfG 116, 77 en Neue Juristische Wochenschrift 1981, p. 1431.

Tribunal Constitucional Español, STC 142/2009.

Tribunal Supremo Español, Sentencia No 243 de 25 de enero de 2013. 